\title{
BMJ Open Prevalence of chemopreventive agent use among hospitalised women at high risk for breast cancer: a cross-sectional study
}

\author{
Waseem Khaliq, ${ }^{1}$ Danijela Jelovac, ${ }^{2}$ Scott M Wright ${ }^{1}$
}

To cite: Khaliq W, Jelovac D, Wright SM. Prevalence of chemopreventive agent use among hospitalised women at high risk for breast cancer: a cross-sectional study. BMJ Open 2016;6:e012550. doi:10.1136/bmjopen-2016012550

- Prepublication history for this paper is available online. To view these files please visit the journal online (http://dx.doi.org/10.1136/ bmjopen-2016-012550).

Received 10 May 2016 Revised 19 July 2016 Accepted 28 September 2016

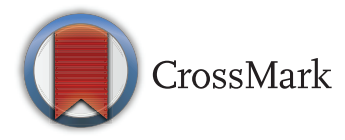

${ }^{1}$ Department of Medicine, Johns Hopkins Bayview Medical Center, Johns Hopkins University, School of Medicine, Baltimore, Maryland, USA 2Johns Hopkins Sidney Kimmel Comprehensive Cancer Center, Johns Hopkins University, School of Medicine, Baltimore, Maryland, USA

Correspondence to Dr Waseem Khaliq; wkhaliq1@jhmi.edu

\section{ABSTRACT}

Objective: To characterise the current usage of chemoprevention agents among hospitalised women who are at higher risk for breast cancer.

Study design: A cross-sectional study.

Setting: Academic hospital at Baltimore.

Participants: A bedside survey of 250 women aged 50-75 years was conducted who were cancer-free at the time of study enrolment and hospitalised to a general medicine service. Reproductive history, family history for breast cancer, chemopreventive agents use and medical comorbidities data was collected for all patients. $\chi^{2}$ and t-tests were used to analyse population characteristics.

Primary outcome measures: Prevalence of women at high risk for developing breast cancer (5-year Gail risk score $\geq 1.7$ ) and their chemopreventive agent use. Results: Mean age for the study population was 61.5 years (SD 7.5), and mean 5-year Gail risk score was 1.67 (SD 0.88). A third of study population was at high risk for breast cancer. None of the high-risk women $(0 \%)$ were taking chemoprevention for breast cancer risk reduction, and $23 \%$ were at very high risk with 5 -year Gail score $\geq 3 \%$. These women were not recognised as being high risk by their hospital providers and none were referred to the high-risk breast cancer clinics following discharge.

Conclusions: Many hospitalised women are at high risk for breast cancer and we could not identify even a single woman who was using chemoprevention for risk reduction. Current chemoprevention guidelines may be falling short in their dissemination and implementation. Since women at high risk for breast cancer may only interface with the healthcare system at select points, all healthcare providers must be willing and able to do risk assessment. For those identified to be at high risk, providers must then either engage in chemopreventive counselling or refer patients to providers who are more comfortable working with patients on this critical decision.

\section{INTRODUCTION}

Breast cancer is the second leading cause of cancer death among women in the USA. ${ }^{1}$

\section{Strengths and limitations of this study}

- The study represents first inquiry evaluating breast cancer risk among hospitalised women and selective oestrogen receptor modulators usage among women at high risk for breast cancer (5-year risk prediction using Gail model $\geq 1.7 \%$ ).

- A comprehensive review of clinical comorbidity burden including Charlson comorbidity index and 11 additional comorbidities.

- The study was conducted at a single hospital and may not have accounted for all relevant factors that could potentially confound or are contraindication with chemoprevention use.

- It is unknown whether the pattern of high-risk status and chemoprevention usage remains stable over time as the study only represents results at single point in time.

Screening mammography is the test of choice for early detection of breast cancer for women at average risk for breast cancer. ${ }^{2}$ Approximately $15 \%$ of women in the USA aged 35-79-years are at high risk for developing breast cancer, however $<0.2 \%$ of these women reported taking chemoprevention to reduce their risk. ${ }^{3}{ }^{4}$ Recently, the American Society of Clinical Oncology (ASCO), the USA Preventive Services Task Force (USPSTF) and the National Comprehensive Cancer Network (NCCN) updated their guidelines for chemopreventive therapy for women at high risk for breast cancer; the recommendations involve the selective oestrogen receptor modulators (SERMs). ${ }^{5-7}$

To reduce the incidence of breast cancer, the USPSTF recommends physicians to impart information, to engage in shared decision-making, and to offer to prescribe risk-reduction medications-if appropriate for asymptomatic women aged $\geq 35$ years without a prior diagnosis of breast cancer who are at increased risk for the disease. ${ }^{8}$ 
ASCO recommends that in women at increased risk of breast cancer age above 35 years, tamoxifen $(20 \mathrm{mg}$ per day for 5 years) should be discussed as an option to reduce the risk of oestrogen receptor (ER)-positive breast cancer. ${ }^{5}$ In postmenopausal women, raloxifene (60 $\mathrm{mg}$ per day for 5 years) and exemestane (25 $\mathrm{mg}$ per day for 5 years) are viable options for breast cancer risk reduction to be discussed with patients. ${ }^{5}$ NCCN guidelines make similar recommendations for women who have $\mathrm{a} \geq 1.7 \%$ 5-year risk for breast cancer. ${ }^{9}$ Much of the enthusiasm for providing individualised breast cancer prevention through risk reduction is based on the Breast Cancer Prevention Trial (BCPT) that showed that SERMs use reduces breast cancer incidence by almost $50 \%$ among women at high risk for breast cancer. ${ }^{10}$ Across ASCO, USPSTF, and NCCN, no single cut-off has been agreed on for defining high-risk status. ${ }^{5-7}$ In research, some clinical trials define increased risk as a 5 -year risk for invasive breast cancer of $1.66 \%$ or greater (as determined by the BCPT) ${ }^{10}$ while others have placed the threshold higher at $3 \%$ or greater. $^{6}$

The aim of our study was to determine the prevalence of high-risk breast cancer status (defined as a 5-year risk for invasive breast cancer of $1.7 \%$ or greater) among hospitalised women age 50-75-year, and to explore the frequency of SERMs use in this cohort. We hypothesised that the prevalence of high-risk status and their SERMs usage would be similar to that of the general population.

\section{METHODS}

\section{Study population and design}

Detailed enrolment methods have been published. ${ }^{11}$ Briefly, 427 women hospitalised to general medicine service at Johns Hopkins Bayview Medical Center were eligible for study participation during the study period (October 2011 to March 2012). Of these hospitalised women, $59(14 \%)$ refused to participate, $47(11 \%)$ were excluded due to history of breast cancer and $71(17 \%)$ women were discharged from the hospital before the study coordinator could consent them. This left a study population with 250 women.

\section{Procedures}

Data was collected via bedside interviews survey that included questions regarding sociodemographic information such as race, education and annual house hold income. The disease burden was evaluated by probing for the presence of medical comorbidities, including those needed for calculating the Charlson comorbidity index (CCI). ${ }^{12}$ Healthcare access was assessed by health insurance status and whether patients had a primary care doctor.

Family history of breast cancer was judged to be positive in patients reporting a breast cancer diagnosis in firstdegree relatives (namely mother, sisters or daughters). Several questions regarding reproductive history were asked such as patients' age at menarche, age at first live childbirth, personal history of ductal carcinoma in situ or lobular carcinoma in situ, number of first-degree relatives with breast cancer and personal history of breast biopsy in order to generate the 'Gail Risk Prediction Score'which estimates the probability of developing breast cancer within the next 5 years according to the National Cancer Institute Breast Cancer Risk Tool. ${ }^{13-18}$ Women were then stratified as high risk for breast cancer if their 5-year risk for breast cancer was $1.7 \%$ or greater. SERMs use and medical documentation about their breast cancer risk status was ascertained via chart review of their incident hospital records.

The study participants provide their written informed consent for study participation.

\section{Statistical analysis}

Respondent characteristics are presented as proportions and means. Unpaired t-test and $\chi^{2}$ tests were used to compare demographic and socioeconomic characteristics based on breast cancer risk stratification, 5-year risk for breast cancer $<1.7 \%$ versus $1.7 \%$ or greater. The data were analysed using the Stata statistical software (StataCorp LP, V.13.1).

\section{RESULTS}

The mean age of the study population was 61.5 years and the mean 5-year risk prediction for breast cancer was $1.67 \%$ (SD 0.88). Thirty-two per cent of women were at high risk for breast cancer defined as 5-year-risk prediction score $\geq 1.7 \%$. Forty-two per cent of women were nonadherent to breast cancer screening recommendations meaning they were overdue for mammography. About $31 \%$ of study participants were African-American and only $6 \%$ were uninsured. Characteristics of the study participants are shown in table 1 . While most variables were similar across the two groups (5-year-risk prediction score $<1.7 \%$ vs 5 -year-risk prediction score $\geq 1.7 \%$ by Gail score), age and family history for breast cancer were not as the breast cancer risk assessment model uses these variables to predicted risk.

The total number of comorbidities and proportion of women with $\geq 3$ comorbidities were also significantly greater among women with a 5-year breast cancer risk $\geq 1.7 \%$, (table 2). A significant and directly proportion association trend was noted between mean CCI and mean 5 -year breast cancer Gail risk prediction score across increasing age groups as shown in figure $1(\mathrm{p}<0.001)$.

In reviewing the medical records, not a single hospital provider documented breast cancer risk status among the women they cared for; failing to do so in initial assessment at the time of admission, daily notes or discharge summaries. Similarly, there was no documentation related to counselling high-risk women (those with a 5-year breast cancer risk $\geq 1.7 \%$ ) about their increased risk for developing breast cancer. Of note, none of these women were on SERMs at the time of hospitalisation, no SERMs were initiated in the hospital and none referred to the high-risk breast cancer clinic following discharge. 
Table 1 Characteristics of the study population by breast cancer risk stratification

\begin{tabular}{|c|c|c|c|c|}
\hline Characteristics & $\begin{array}{l}\text { All study } \\
\text { population } \\
(\mathrm{N}=250)\end{array}$ & $\begin{array}{l}\text { Five-year-risk prediction } \\
\text { using Gail model }<1.7 \% \\
(\mathrm{~N}=169)\end{array}$ & $\begin{array}{l}\text { Five-year-risk prediction } \\
\text { using Gail model } \geq 1.7 \\
(\mathrm{~N}=81)\end{array}$ & p Value* \\
\hline Age in years, mean (SD) & $61.5(7.5)$ & $59.8(7.2)$ & $65.2(6.9)$ & $0.000 \dagger$ \\
\hline \multicolumn{5}{|l|}{ Race } \\
\hline Caucasians, n (\%) & $164(66)$ & $105(62)$ & $59(73)$ & \multirow[t]{3}{*}{0.22} \\
\hline African-American, n (\%) & 77 (31) & $58(34)$ & $19(23)$ & \\
\hline Others, n (\%) & $9(3)$ & $6(4)$ & $3(4)$ & \\
\hline $\begin{array}{l}\text { High school or more years of } \\
\text { education, } n(\%)\end{array}$ & $168(67)$ & $112(66)$ & $56(69)$ & 0.65 \\
\hline Employed, n (\%) & $51(20)$ & $39(23)$ & $12(15)$ & 0.17 \\
\hline $\begin{array}{l}\text { Chronic disable, wheel chair } \\
\text { or bed bound } n(\%)\end{array}$ & $105(42)$ & $64(38)$ & $41(51)$ & 0.06 \\
\hline $\begin{array}{l}\text { Family history of breast } \\
\text { cancer, } \mathrm{n}(\%) \ddagger\end{array}$ & $34(14)$ & $0(0)$ & $34(42)$ & 0.00 \\
\hline \multicolumn{5}{|l|}{$\mathrm{BMI} \mathrm{kg} / \mathrm{m}^{2}, \mathrm{n}(\%)$} \\
\hline$<25$ & $49(20)$ & $40(24)$ & $9(11)$ & \multirow[t]{3}{*}{0.05} \\
\hline $25-29.9$ & $59(23)$ & $40(24)$ & $19(23)$ & \\
\hline$\geq 30$ & $142(57)$ & $89(53)$ & $53(65)$ & \\
\hline $\begin{array}{l}\text { Annual household income < } \\
\$ 20000, \mathrm{n}(\%) \S\end{array}$ & $148(61)$ & $96(60)$ & $52(65)$ & 0.42 \\
\hline Uninsured, n (\%) & $15(6)$ & $11(6.5)$ & $4(5)$ & 0.63 \\
\hline $\begin{array}{l}\text { Non-adherence to screening } \\
\text { mammography, } \mathrm{n}(\%) \emptyset\end{array}$ & $104(42)$ & $75(44)$ & $29(36)$ & 0.19 \\
\hline $\begin{array}{l}\text { No primary care physician, } \\
\mathrm{n}(\%)\end{array}$ & $23(9)$ & $16(9)$ & $7(8)$ & 0.83 \\
\hline Current smoker, n (\%) & $73(29)$ & $56(33)$ & $17(21)$ & 0.04 \\
\hline Alcohol use, n (\%) & $38(15)$ & $28(17)$ & $10(12)$ & 0.38 \\
\hline $\begin{array}{l}\text { Length of stay in days, } \\
\text { mean (SD) }\end{array}$ & $5.3(10)$ & $5.5(12)$ & $4.7(3.4)$ & $0.56 \dagger$ \\
\hline \multicolumn{5}{|c|}{$\begin{array}{l}{ }^{*} \chi^{2} \text { test. } \\
\dagger \text { Unpaired t-test statistic. } \\
\text { tFamily History of breast cancer was defined as breast cancer in first-degree relatives like mother, sisters or daughters. } \\
\text { §Nine patients elected not to answer the question. }\end{array}$} \\
\hline
\end{tabular}

\section{DISCUSSION}

This study represents the first inquiry evaluating breast cancer risk among hospitalised women and SERMs utilisation in those at highest risk for breast cancer. We found that almost one-third of the hospitalised women age 50-75 years were at high risk for breast cancer as assessed by Gail model 5-year risk prediction of $\geq 1.7 \%$. Their high risk does not appear to have been noticed or considered during the hospitalisations and none were referred to high-risk clinic following discharge or for a mammogram that was overdue. Not a single patient was taking SERMs for breast cancer risk reduction and this is not drastically different from population data that has shown that $<0.2 \%$ of women who are at high risk for breast cancer were using chemoprevention. ${ }^{4}$

SERMs usage has not been widely implemented despite data showing a $50 \%$ risk reduction in the breast cancer incidence and Food and Drug Administration approval in $1998 .^{10}$ Presenting effectiveness of any intervention by presenting supporting evidence in relative terms can lead to skepticism and confusion among patients and physicians. ${ }^{19}$ Therefore, proof of evidence can be better summarise by number needed to treat (NNT), along with absolute risk reduction. According to BCPT, the NNT with daily tamoxifen for more than 5 years to prevent one case of breast cancer is 48 women. ${ }^{10}$ This NNT varies across other SERMS studies with the lowest being for anastrozole in the IBIS-II trial. $^{19-21}$ In IBIS-11, the NNT with anastrozole to prevent one case of breast cancer in 7 years was 36 women. ${ }^{21}$ These NNTs compare favourably with interventions commonly recommended by primary care physicians; for example, the NNT is 60 persons for the use of statins for the primary prevention of myocardial infarction. $^{22}$

Freedman et $a \hat{l}$ estimated that over 2 million women in the USA could benefit from chemoprevention to reduce the risk of breast cancer. National Health Interview Survey data from 2010 suggest that overall usage of SERMs did not increase from 2000 to 2010, except for a slight increase in the use of raloxifene in postmenopausal women. ${ }^{4}$ The postulated reasons for the limited uptake in chemoprevention use include lack of awareness among high-risk women and their 
Table 2 Comorbidities and disease burden by breast cancer risk stratification

\begin{tabular}{|c|c|c|c|c|}
\hline Comorbidities & $\begin{array}{l}\text { All } \\
(N=250)\end{array}$ & $\begin{array}{l}\text { Five-year-risk } \\
\text { prediction using Gail } \\
\text { model }<1.7 \%(\mathrm{~N}=169)\end{array}$ & $\begin{array}{l}\text { Five-year-risk } \\
\text { prediction using Gail } \\
\text { model } \geq 1.7(\mathrm{~N}=81)\end{array}$ & p Value* \\
\hline $\begin{array}{l}\text { Age adjusted Charlson comorbidity index } \\
(\mathrm{CCl}) \text { score }>3, \mathrm{n}(\%) \dagger\end{array}$ & $156(62)$ & $100(59)$ & $56(69)$ & 0.13 \\
\hline \multicolumn{5}{|c|}{ Age adjusted Charlson comorbidity index (CCI) score† } \\
\hline $0-3, \mathrm{n}(\%)$ & $94(38)$ & $69(41)$ & $25(31)$ & \multirow[t]{5}{*}{0.09} \\
\hline $4-5, n(\%)$ & $85(34)$ & $55(33)$ & $30(37)$ & \\
\hline $6-7, \mathrm{n}(\%)$ & $42(17)$ & $31(18)$ & $11(14)$ & \\
\hline $8-9, n(\%)$ & $24(10)$ & $11(7)$ & $13(16)$ & \\
\hline 10 or above, $n(\%)$ & $5(2)$ & $3(2)$ & $2(2)$ & \\
\hline Hypertension, n (\%) & $212(85)$ & $135(80)$ & $77(95)$ & 0.002 \\
\hline Heart disease, $\mathrm{n}(\%)$ & $80(32)$ & $48(28)$ & $32(40)$ & 0.08 \\
\hline Hypercholesterolaemia, n (\%) & $148(59)$ & $93(55)$ & $55(68)$ & 0.05 \\
\hline Atrial fibrillation, $\mathrm{n}(\%)$ & $26(10)$ & $13(8)$ & $13(16)$ & 0.04 \\
\hline History of pulmonary embolism, n (\%) & $14(6)$ & $10(6)$ & $4(5)$ & 0.75 \\
\hline History of deep venous thrombosis, n (\%) & $28(11)$ & $17(10)$ & $11(14)$ & 0.40 \\
\hline Total morbidities excluding $\mathrm{CCl}$, mean (SD) & $3.95(2)$ & $3.69(2)$ & $4.5(2)$ & $0.003 \ddagger$ \\
\hline Three or more comorbidities, $\mathrm{n}(\%) \S$ & $187(75)$ & $117(70)$ & $70(86)$ & 0.003 \\
\hline \multicolumn{5}{|c|}{$\begin{array}{l}{ }^{*} \chi^{2} \text { test. } \\
\text { †Unpaired t-test statistic. } \\
\text { †Charlson comorbidity index }(\mathrm{CCl}) \text { scores of } 0,1,2 \text { and } 3 \text { predicting } 10 \text {-year survival rates of } 93 \%, 73 \%, 52 \% \text { and } 45 \% \text {, respectively. } \\
\text { §Comorbidities excluded diseases accounted for } \mathrm{CCI} \text { and includes: hypertension, heart disease, hypercholesterolaemia, atrial fibrillation, } \\
\text { history of pulmonary embolism or deep venous thrombosis, obstructive sleep apnoea, osteoporosis, depression, chronic hepatitis, } \\
\text { hypothyroidism, nephrolithiasis and anaemia. }\end{array}$} \\
\hline
\end{tabular}

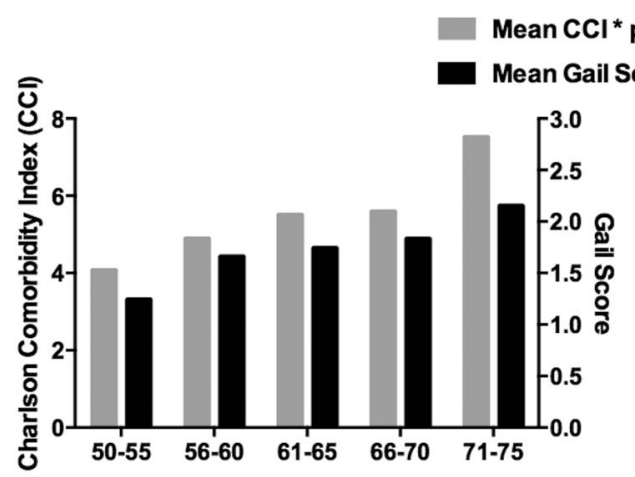

Age Groups

${ }^{*} \mathrm{Chi}$-Square test-p value for difference in mean $\mathrm{CCl}$ and Gail score of hospitalised women between age groups.

Figure 1 Effect of age on comorbidities and breast cancer risk among hospitalised women.

healthcare providers, difficulty in identifying the ideal candidates and concerns about adverse effects of the agents. ${ }^{22}$ Identifying the optimal candidates for chemoprevention strategies continues to be imperfect. Ongoing research is examining novel ways to administer SERMs in hopes of reducing side effects, thereby increasing the medication's acceptability and adherence. $^{23}$

Current breast cancer risk-assessment models do not incorporate all known risk factors, such as density of breast tissue, and history of radiation exposure. The lack of agreement on a specific threshold for considering risk reduction therapy, and the absence of campaigns to incorporate breast cancer risk assessment into patient care across clinical settings may explain why SERMs continues to be so low. The Breast Cancer Risk Assessment Tool, although widely used, does not discriminate well at the individual level, especially for women at higher levels of risk or with complex family history for breast and ovarian cancers. ${ }^{24}$ Since both Gail score and CCI increase with age (figure 1), it might be worthwhile if revised guideline provides clarity about the clinical comorbidity burden or age when not to consider chemoprevention for breast cancer risk reduction. Perhaps the threshold to consider starting chemoprevention should take into accounts both woman's age and comorbidity status to optimise its utility.

In such circumstances, clinical reasoning must be factored into the application of model-based predictions to determine an individual's appropriateness for genetic testing and/or preventive treatment. ${ }^{24}$ Ascertaining breast cancer risk for the individual patient is straightforward with the Gail score and online calculator (http:// www.cancer.gov/bcrisktool/). Communicating what this means to the patient that a physician is caring for can be challenging for any physician, including the hospitalist provider. Determining the optimal timing for such a discussion, after the patient is clinically stable and discharge planning has begun, has yet to be determined. This reliance on judgement and experience may continue to preclude having more physicians feeling comfortable with initiating chemoprevention. 
Several limitations of this study should be considered. First, this study was conducted at a single hospital. Second, we evaluated clinical comorbidity burden fairly comprehensively. However, we may not have accounted for all relevant factors that could potentially confound or are contraindication with chemoprevention use. For example, it is possible that a small proportion of the highrisk women were not on chemopreventive agents for primary prevention of breast cancer due to contraindications of SERMs use like a prior history for pulmonary embolism or deep venous thrombosis. Third, it is unknown whether the pattern of high-risk status and chemoprevention usage remains stable over time. Our data was collected over several months but this still represents only a single point in time. Fourth, we did not ask the high-risk women in our study if they had ever been informed of their risk status or if they had been encouraged to use SERMs. Finally, one could argue that implications of this study would be most relevant only if these high-risk women would actually agree to take chemopreventive agents following appropriate education and counselling. While this question is beyond the scope of this study's inquiry, research efforts will be needed to understand the best practices for having these conversations.

\section{Conclusion}

There is a need to optimise breast cancer risk assessment and chemoprevention implementation initiatives in order to decrease the incidence of breast cancer. Targeting the women at high risk for breast cancer whenever and wherever they interact with our healthcare systems may be necessary. While it is not yet common practice for hospitalist physicians to extensively review preventive care needs of their patients, in accountable care organisations we all share in the responsibility for maintaining health and averting disease.

Acknowledgements Dr Wright is a Miller-Coulson Family Scholar supported by Hopkins Center for Innovative Medicine.

Contributors WK and SMW participated in study design and drafted the manuscript. WK performed the statistical analysis. DJ helped draft manuscript and provided suggestions. All authors reviewed the manuscript.

Funding This work was made possible in part by the Maryland Cigarette Restitution Fund Research Grant at Johns Hopkins.

\section{Competing interests None declared.}

Ethics approval Institutional Review Board at Johns Hopkins Bayview Medical Center.

Provenance and peer review Not commissioned; externally peer reviewed.

Data sharing statement No additional data are available.

Open Access This is an Open Access article distributed in accordance with the Creative Commons Attribution Non Commercial (CC BY-NC 4.0) license, which permits others to distribute, remix, adapt, build upon this work noncommercially, and license their derivative works on different terms, provided the original work is properly cited and the use is non-commercial. See: http:// creativecommons.org/licenses/by-nc/4.0/

\section{REFERENCES}

1. American Cancer Society. Breast cancer facts \& figures 2015-2016. Atlanta: American Cancer Society, ., 2015.

2. Hendrick RE, Helvie MA. United States preventive services task force screening mammography recommendations: science ignored. AJR Am J Roentgenol 2011;196:W112-16.

3. Freedman AN, Graubard BI, Rao SR, et al. Estimates of the number of US women who could benefit from tamoxifen. J Natl Cancer Inst 2003;95:526-32.

4. Waters EA, Cronin KA, Graubard $\mathrm{BI}$, et al. Prevalence of tamoxifen use for breast cancer chemoprevention among US women. Cancer Epidemiol Biomarkers Prev 2010;19:443-6.

5. Visvanathan K, Hurley P, Bantug E, et al. Use of pharmacologic interventions for breast cancer risk reduction: American Society of Clinical Oncology clinical practice guideline. J Clin Oncol 2013;31:2942-62.

6. Moyer VA, LeFevre ML, Siu AL, et al. Medications to decrease the risk for breast cancer in women: recommendations from the U.S. Preventive Services Task Force recommendation statement. Ann Intern Med 2013;159:698-708. http://www.uspreventiveservice staskforce.org/Page/Document/RecommendationStatementFinal/ breast-cancer-medications-for-risk-reduction

7. Bevers TB, Ward JH, Arun BK, et al. Breast cancer risk reduction, version 2. J Natl Compr Canc Netw 2015;13:880-915.

8. Final Update Summary: Breast Cancer: Medications for Risk Reduction. U.S. Preventive Services Task Force. July 2015. http:// www.uspreventiveservicestaskforce.org/Page/Document/ UpdateSummaryFinal/breast-cancer-medications-for-risk-reduction

9. http://www.nccn.org/professionals/physician_gls/pdf/breast_risk.pdf

10. Fisher B, Costantino JP, Wickerham DL, et al. Tamoxifen for prevention of breast cancer: a report of the National Surgical Adjuvant Breast and Bowel Project P-1. J Natl Cancer Inst 1998:90:1371-88.

11. Khaliq W, Visvanathan $\mathrm{K}$, Landis $\mathrm{R}$, et al. Breast cancer screening preferences among hospitalized women. $J$ Womens Health (Larchmt) 2013;22:637-42.

12. Charlson ME, Pompei P, Ales KL, et al. A new method of classifying prognostic comorbidity in longitudinal studies: development and validation. J Chronic Dis 1987;40:373-83.

13. Gail MH, Brinton LA, Byar DP, et al. Projecting individualized probabilities of developing breast cancer for white females who are being examined annually. J Natl Cancer Inst 1989;8:1879-86.

14. Costantino JP, Gail MH, Pee D, et al. Validation studies for models projecting the risk of invasive and total breast cancer incidence. J Natl Cancer Inst 1999;91:1541-8.

15. Gail MH, Costantino JP, Bryant J, et al. Weighing the risks and benefits of tamoxifen treatment for preventing breast cancer. $J$ Natl Cancer Inst 1999;91:1829-46.

16. Rockhill B, Spiegelman D, Byrne C, Validation of the Gail et al. model of breast cancer risk prediction and implications for chemoprevention. J Natl Cancer Inst 2001;93:358-66.

17. Gail MH, Costantino JP, Pee D, et al. Projecting individualized absolute invasive breast cancer risk in African-American women. $J$ Natl Cancer Inst 2007;99:1782-92.

18. Matsuno RK, Costantino JP, Ziegler RG, et al. Projecting individualized absolute invasive breast cancer risk in Asian and Pacific Island American women. J Natl Cancer Inst 2011;103:951-61.

19. King NB, Harper S, Young ME. Use of relative and absolute effect measures in reporting health inequalities: structured review. BMJ 2012;345:e5774.

20. Cauley JA, Norton L, Lippman ME, et al. Continued breast cancer risk reduction in postmenopausal women treated with raloxifene: 4-year results from the MORE trial. Multiple outcomes of raloxifene evaluation. Breast Cancer Res Treat 2001;65:125-34.

21. Advani P, Moreno-Aspitia A. Current strategies for the prevention of breast cancer. Breast Cancer (Dove Med Press) 2014;6:59-71.

22. Taylor F, Huffman MD, Macedo AF, et al. Statins for the primary prevention of cardiovascular disease. Cochrane Database Syst Rev 2013;1:CD004816.

23. Karavites LC, Allu S, Khan SA, et al. Awareness of preventive medication among women at high risk for breast cancer and their willingness to consider transdermal or oral tamoxifen: a focus group study. BMC Cancer 2015;15:878.

24. Amir E, Freedman OC, Seruga B, et al. Assessing women at high risk of breast cancer: a review of risk assessment models. $J$ Natl Cancer Inst 2010;102:680. 